\title{
Treg and Th17 cells in inflammatory periapical disease: a systematic review
}

\begin{abstract}
André Oliveira NAUFEL ${ }^{(a)}$ Maria Cássia Ferreira AGUIAR ${ }^{(a)}$ Fernandes Moreira MADEIRA ${ }^{(b)}$ Lucas Guimarães ABREU(c)
\end{abstract}

(a) Universidade Federal de Minas Gerais UFMG, School of Dentistry, Department of Oral Surgery and Pathology, Belo Horizonte, MG, Brazil.

(b) Universidade Federal de Minas Gerais UFMG, Institute of Biological Sciences, Department of Microbiology. Belo Horizonte, MG, Brazil.

(c) Universidade Federal de Minas Gerais UFMG, School of Dentistry, Department of Pediatric Dentistry and Orthodontics, Belo Horizonte, MG, Brazil.

Declaration of Interests: The authors certify that they have no commercial or associative interest that represents a conflict of interest in connection with the manuscript.

Corresponding Author:

André Oliveira Naufel

E-mail: andrennaufel@hotmail.com

https://doi.org/10.1590/1807-3107bor-2017.vol31.0103

Submitted: June 20, 2017

Accepted for publication: Oct 10, 2017

Last revision: Nov 09,2017
Abstract: The process involved in periapical lesions, which occur as an outcome of pulpal necrosis, is regulated by the immune system including regulatory T cells (Treg) and T helper 17 cell (Th17) responses. The objective of this study was to conduct a frequency systematic review to determine the presence of Treg/Th17 responses and the influence of these cells in the progression of chronic inflammatory periapical lesions in humans. A systematic computerized search was carried out in Pubmed, Medline, Web of Science and Scopus electronic databases from their date of inception through the first week of May 2017. In addition, the reference lists of the included articles and the grey literature were hand-searched. Articles that evaluated the presence and influence of Treg/Th17 in the progression of human periapical lesions were included. Study selection and the quality assessment of the included articles (using the Newcastle-Ottawa scale) were carried out by two authors. Fifty-seven titles/abstracts were screened and eight studies met the eligibility criteria and were included in this systematic review. The included studies showed large variation in the type of periapical lesion assessed, mean age, age range, type of experiment and findings regarding the participation of Th17 and Treg in the status of inflammatory periapical lesions. The studies showed the involvement of Treg in the modulation of the inflammatory response in radicular cysts and periapical granulomas. This systematic review highlights the relationship between Treg and Th17 acting in a subtle balance inhibiting or promoting the progression of human periapical lesions.

Keywords: Periapical Diseases; T-Lymphocytes, Regulatory; Th17 Cells.

\section{Introduction}

Apical chronic periodontitis is a common inflammatory osteolytic disease of the jaws. The process is regulated by several inflammatory mediators including cytokines released by leukocytes. ${ }^{1}$ Leukocytes are recruited from the periapical tissues in response to intracanal bacterial infection, and the persistence of the antigenic stimulus can result in chronic periapical lesions such as periapical granuloma and radicular cyst. ${ }^{2}$

The role of immunological mechanisms in the pathogenesis of periapical lesions has been widely documented. ${ }^{3}$ The interplay between immune regulatory mechanisms and effector $\mathrm{T}$ cell responses is a crucial 
determinant of innate and adaptive immunity. ${ }^{4} \mathrm{CD} 4^{+}$ $\mathrm{T}$ cells play a regulatory role and help to constrain the effector function of other cell types. ${ }^{5}$ More recently, ${ }^{6}$ the identification of CD4+ Foxp3+ regulatory T cells (Treg) and T helper 17 cells (Th17) modified the paradigm Th1-Th2. The Treg-Th17 pair has explained the immunity/inflammation process in an increasing number of diseases, including periodontal disease and others involving progressive bone resorption. ${ }^{7}$

Tregs, defined by the expression of the lineagespecific transcription factor FoxP3 (Forkhead box P3), are cells required for immune induction. ${ }^{8}$ Th17 play critical roles in the progression of autoimmunity and inflammation by the production of IL-17 and require specific cytokines for their differentiation, such as the transforming growth factor- $\beta$ (TGF- $\beta$ ), which may be combined with interleukin-6 (IL-6) or IL-21 and the transcription factor ROR $\gamma \mathrm{t} .{ }^{9}$ The participation of Treg and Th17 in the inflammatory response may help explain many unresolved issues in the immunobiology of periapical lesions, such as bone resorption occurring in different manners as a reflection of intracanal infection in similar cases of pulpal necrosis..$^{10}$ However, the up or down regulation of both Foxp3 and Th17 in periapical inflammatory disease has been explored mostly in animal models, ${ }^{1,9,11}$ with few studies conducted in humans, in different types of chronic lesions, such as radicular cysts or periapical granuloma. Thus, defining the role of Treg/Th17 is crucial for better understanding the immune system regulation of these lesions.

This frequency systematic review aimed to demonstrate the presence of Treg and Th17 in human inflammatory chronic disease and to describe the effects of these subsets of cells in the immuneinflammatory status of periapical lesions in humans.

\section{Methods}

\section{Protocol and registration}

This systematic review was designed using the Preferred Reporting Items for Systematic Reviews and Meta-Analyses checklist (PRISMA) as a template, ${ }^{12}$ and was registered in the International Prospective Register of Systematic Reviews (PROSPERO) under the number CRD42017077714.

\section{Eligibility criteria}

Studies evaluating the role of Th17 and Treg in the progression of human periapical lesions were included. The pathway of the Treg/Th17 and the involved biomarkers is shown in Figure 1. The following PECOS question has been applied:

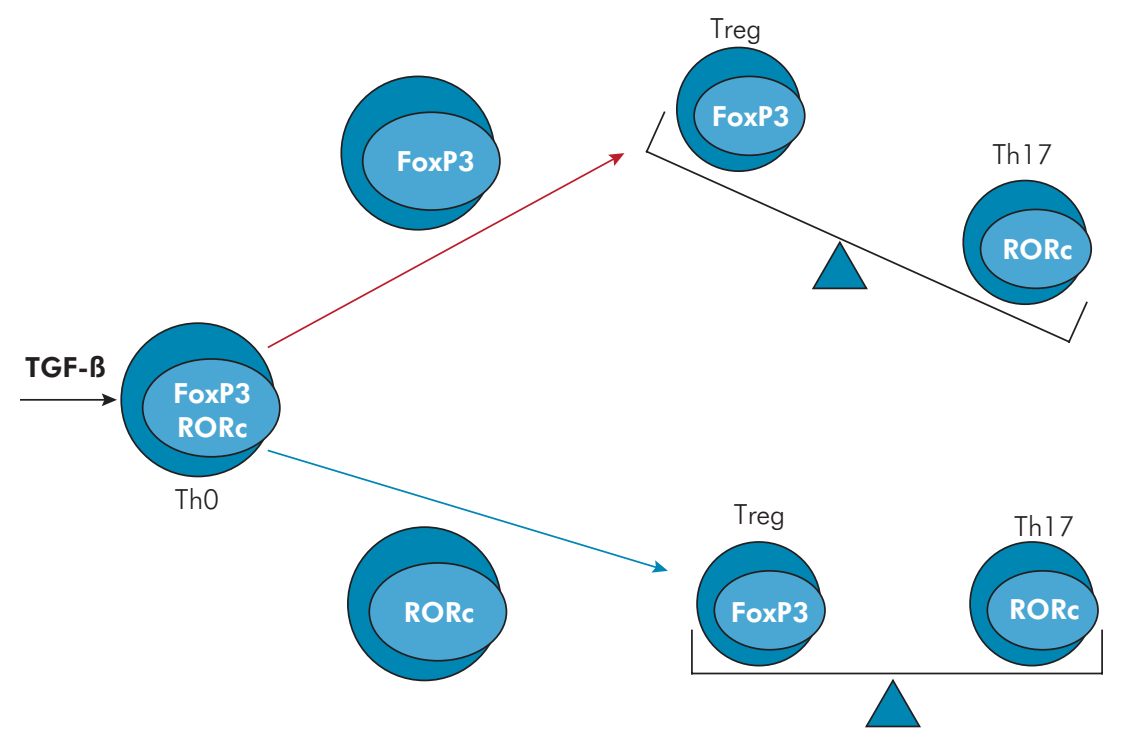

Figure 1. Imbalance between Th 17 and Treg lymphocytes, mediated by RORc and FoxP3. 
$\mathrm{P}($ problem $)=$ Periapical lesions in humans

$\mathrm{E}($ exposure $)=$ High levels of expression of Treg/Th17 and/or FoxP3/IL-17

$C$ (comparison) $=$ Low levels of expression of Treg/Th17 and/or FoxP3/IL-17

$\mathrm{O}$ (outcome) $=$ Immune inflammatory response

$\mathrm{S}$ (study design) $=$ Observational studies

Reviews, case reports, letters to editors, studies involving animals and meeting abstracts were excluded. No restriction regarding language, date and status of publication was applied.

\section{Information sources}

Systematic computerized searches were carried out using the electronic databases Pubmed, Medline (Ovid SP), Web of Science (Thomson Reuters) and Scopus (Elsevier) from their date of inception through the first week of October 2015 and later updated to the first week of May 2017. Hand searches of the references of the included articles were also carried out in order to identify relevant studies that might have been missed in the electronic search. Finally, a search of the grey literature was conducted using Google Scholar search engine, limited to the first 100 hits. References were managed using the EndNote software (EndNote ${ }^{\mathrm{TM}}$ Thomson Reuters, Philadelphia, PA, USA). Duplicate hits were removed upon identification.

\section{Search}

The searches were conducted with the assistance of a senior librarian. The keywords and appropriate truncations were specific to Pubmed and Medline. The same search strategy was used for Web of Science, Scopus and Google Scholar. The keywords and the number of hits found in each electronic search are presented in Table 1.

\section{Study selection}

Study selection was carried out in two phases. During the first phase, two authors (AONT, MCFA)

Table 1. Search strategy for each each electronic database

\begin{tabular}{|c|c|c|c|}
\hline \multirow[b]{2}{*}{ Database } & \multirow[b]{2}{*}{ Keywords } & \multicolumn{2}{|c|}{ Results } \\
\hline & & Search $1^{*}$ & $\begin{array}{l}\text { Updated } \\
\text { Search }\end{array}$ \\
\hline \multicolumn{4}{|l|}{ Pubmed } \\
\hline & 1 - periapical lesions OR periapical diseases (Mesh) OR radicular cyst (Mesh) OR & 49 & 6 \\
\hline \multicolumn{4}{|c|}{ radicular cysts OR periapical granuloma (Mesh) OR periapical granulomas } \\
\hline \multicolumn{4}{|c|}{2 - † cells, T-lymphocytes (Mesh) OR T lymphocytes OR cd4-Positive T-lymphocytes (Mesh) } \\
\hline \multicolumn{4}{|c|}{ OR T-Lymphocytes, Regulatory (Mesh) OR regulatory T cells OR regulatory cells OR T reg } \\
\hline \multicolumn{4}{|c|}{ OR T reg cells OR Th17 cells (Mesh) OR Th17 OR FOXP3 protein, human (Mesh) OR } \\
\hline \multicolumn{4}{|c|}{ FoxP3 OR forkhead box P3 OR Foxp3+ OR RORC protein, human (Mesh) OR ROR } \\
\hline \multicolumn{4}{|c|}{ OR RORyt OR RORyt OR ror gamma † OR ror gamma OR ror gammat } \\
\hline \multicolumn{4}{|c|}{$3-1$ AND 2} \\
\hline \multicolumn{4}{|l|}{ Medline } \\
\hline \multicolumn{4}{|c|}{$\begin{array}{c}1 \text { - periapical diseases OR periapical lesions }(\mathrm{mp}) \text { OR radicular cyst OR periapical } \\
\text { granuloma }\end{array}$} \\
\hline & $\begin{array}{l}2 \text { - T-Lymphocytes, Regulatory OR regulatory T cells }(\mathrm{mp}) \text { OR Th17 Cells OR Th17 (mp) OR } \\
\text { FOXP3 protein, human }(\mathrm{mp}) \text { OR FoxP3 }(\mathrm{mp}) \text { OR forkhead box P3 }(\mathrm{mp}) \text { OR Foxp3+ (mp) } \\
\text { OR ror gamma } \mathrm{(mp}) \text { OR ror gamma }(\mathrm{mp})\end{array}$ & \multirow[t]{2}{*}{28} & \multirow[t]{2}{*}{5} \\
\hline & $3-1$ AND 2 & & \\
\hline \multicolumn{4}{|l|}{ Scopus } \\
\hline & same as Pubmed & 0 & 0 \\
\hline \multicolumn{4}{|c|}{ Web of Science } \\
\hline & same as Pubmed & 44 & 7 \\
\hline
\end{tabular}

"Up to the first week of October 2015; "From the second week of October 2015 to the first week of May 2017 
independently reviewed the list of titles and abstracts for inclusion; the ones that did not meet the eligibility criteria were excluded. Once potentially adequate abstracts were selected, full-text articles were retrieved. During the second selection phase, the same reviewers independently evaluated full-texts, and those studies that met all eligibility criteria were included in the systematic review. In both phases, disagreements between reviewers were resolved through discussion until achievement of a consensus. A third reviewer was involved when needed for a final decision (MFMM).

\section{Data collection process}

Data collection was independently performed by two authors (AONT, MCFA). Discrepancies were dealt with as above. In case of missing information, contact with authors were planned.

\section{Data items}

Data on the following items were collected: author and date of publication, country where the study was conducted, study design, sample size, type of periapical lesion assessed, mean age, age range, type of experiment used in the included study and findings regarding the participation of Th17 and Treg in the progression of periapical lesions. Data were organized in a standardized table.

\section{Risk of bias}

Risk of bias in individual studies was evaluated according the Newcastle-Ottawa scale..$^{13}$ The scores range of the scale are dependent on the study design. For case-control studies, a quality score was calculated based on group selection (four items), comparability between groups (one item), and outcome and exposure assessment (three items) categories. A maximum of 1 point was awarded for each item in the group selection, and outcome and exposure assessment categories. A maximum of two points was awarded for comparability. Thus, the maximum score of nine points represented the highest methodological quality. A study was categorized as high quality if the total score was 7 or higher. For cross-sectionals studies, the score was calculated based on the same three categories. However, those categories had a different number of items: group selection (two items), comparability (one item), and outcome and exposure assessment (two items). Therefore, the maximum score was 6 for the highest quality. A study was categorized as having high quality if the total score was 4 or higher.

\section{Summary measures}

Any type of statistical method (e.g.: p-value) examining the participation of Th17 and Treg in the progression of periapical lesions was considered.

\section{Synthesis of results}

Heterogeneity was evaluated by means of variability assessment across included articles regarding study design, analytical assay used and the statistical analysis examining the role of Th17 and Treg in the progression of periapical lesions. If data were homogeneous, a meta-analysis would be performed. Instead, if data were heterogeneous, a qualitative summary of results would be carried out.

\section{Risk of bias across studies}

Bias regarding multiple publications was investigated in the present systematic review. The unit of analysis considered was the study, not the publication.

\section{Results}

\section{Study selection}

A total of 121 records were initially identified through the electronic databases. The updated search retrieved 18 records. Following the removal of 82 duplicates, 57 titles/abstracts were screened. Of those, 39 did not meet the eligibility criteria and were excluded. In phase 2, the full-text of 18 studies were retrieved and evaluated. Of those, only eight ${ }^{14,15,16,17,18,19,20,21}$ met the eligibility criteria. No additional study was identified in the reference lists of the included articles and in the grey literature. A flowchart of the study selection for this systematic review is depicted in Figure 2.

\section{Study characteristics}

Among the eight included articles, four were crosssectional studies ${ }^{16,17,19,20}$ and four were case-control studies. ${ }^{14,15,18,21}$ All studies involved human periapical lesion fragments. Samples of six articles ${ }^{14,15,18,19,20,21}$ were 


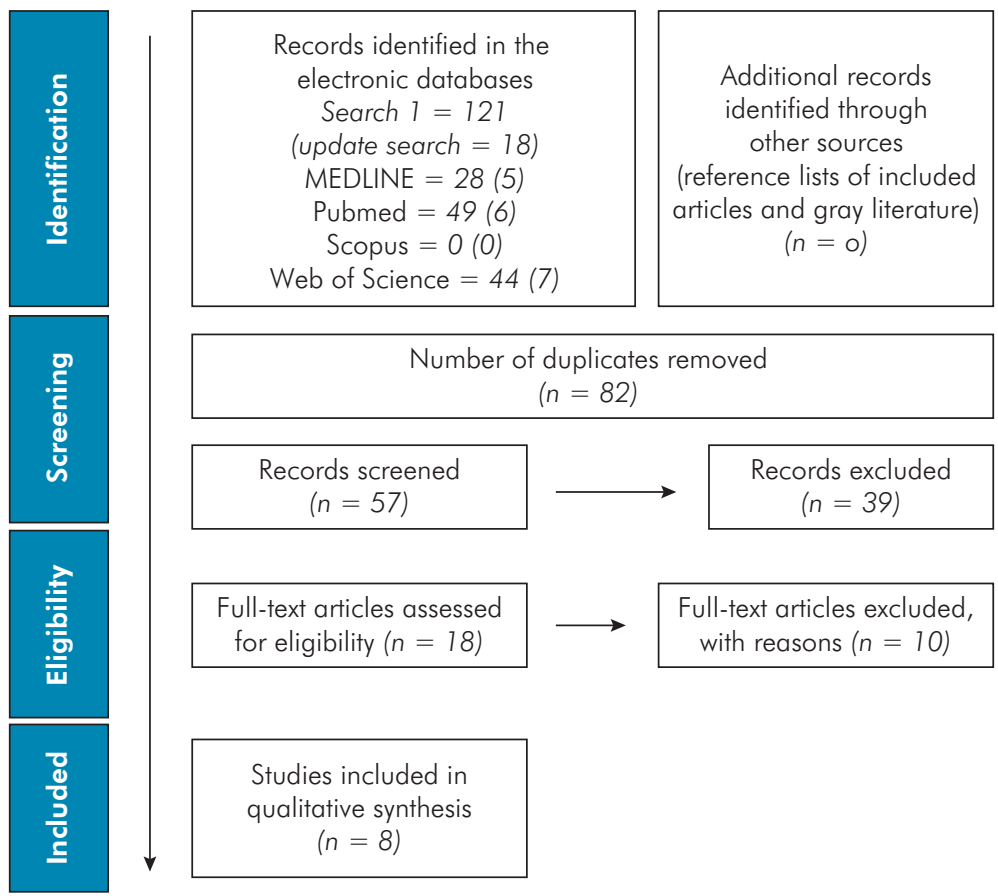

Figure 2. Flowchart of study selection of for this systematic review.

obtained directly through surgery and samples of the other two studies were obtained through institutional archives collected from previous surgical procedures. ${ }^{16,17}$

Four articles reported the mean age of participants ${ }^{18,19,20,21}$ and five studies defined the range between 17 and 64 years. ${ }^{14,15,19,20,21}$ The language of the articles was predominantly English, although the studies were conducted in different countries (Brazil, United States and Serbia). The analytical method used in two studies was the ELISA method. ${ }^{18,20}$ Real-time polymerase chain reaction (RT-PCR) was used in three studies, ${ }^{11,15,21}$ flow cytometry in two studies, ${ }^{19,20}$ confocal microscopy in one study, ${ }_{1}^{19}$ and immunohistochemistry was used in four studies. ${ }^{16,17,18,20}$ The entire description of studies characteristics is shown in Table 2.

\section{Risk of bias within studies}

The cross-sectional studies ${ }^{16,17,19,20}$ were rated between two and three. The case-controls studies ${ }^{14,15,18,21}$ between six and nine.

\section{Results of individual studies}

Different factors were considered in the studies, demonstrating considerable diversity among the indices employed. Lesions were analyzed based on histological and radiographic characteristics to differentiate between periapical granulomas, ${ }^{14,15,16,17,18,21}$ periapical cysts ${ }^{14,21}$ and residual radicular cysts. ${ }^{16,17,18}$ Two articles classified lesions only as periapical, without differentiatinge into granuloma or periapical cysts. ${ }^{19,20}$ A statistically significant association was found between Treg/Th17 markers and clinicopathological features of chronic inflammatory periapical lesions in human tissues. ${ }^{14,15,16,17,18,19,20,21}$

\section{Relationship between Treg/Th17 in periapical lesions}

All immunohistochemical studies employed FoxP3 and cytokine IL-17, the hallmarks of Treg and Th17, respectively, to characterize the Treg/Th17 response in periapical lesions.

In these studies, differences were found between periapical granulomas and radicular cysts. A higher number of FoxP3 cells were found in granulomas than in cysts, ${ }^{16,17}$ although in another study this difference was demonstrated only when comparing lesions and controls. ${ }^{18}$ Studies failed to demonstrate an association between intensity of inflammation and 


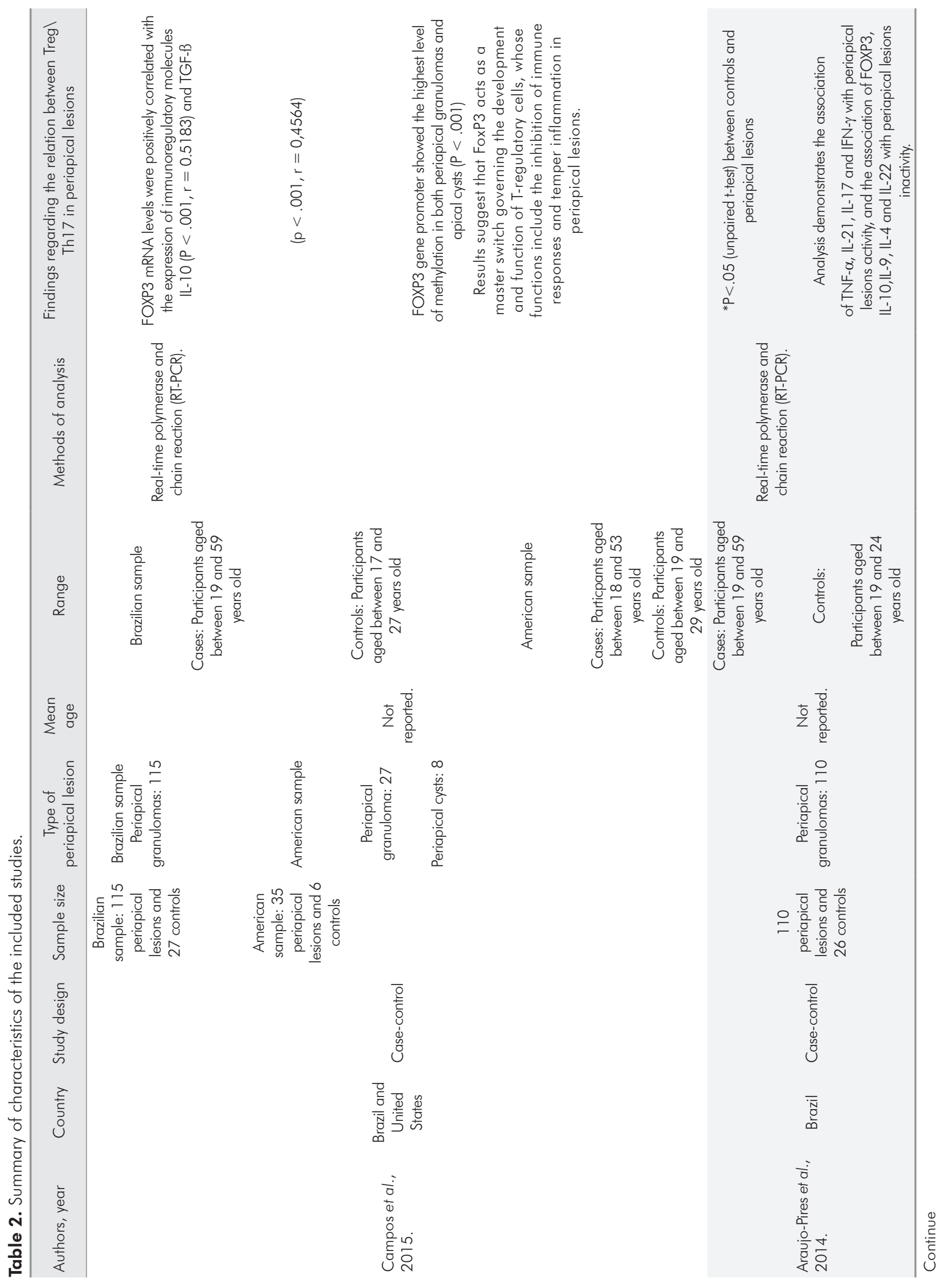




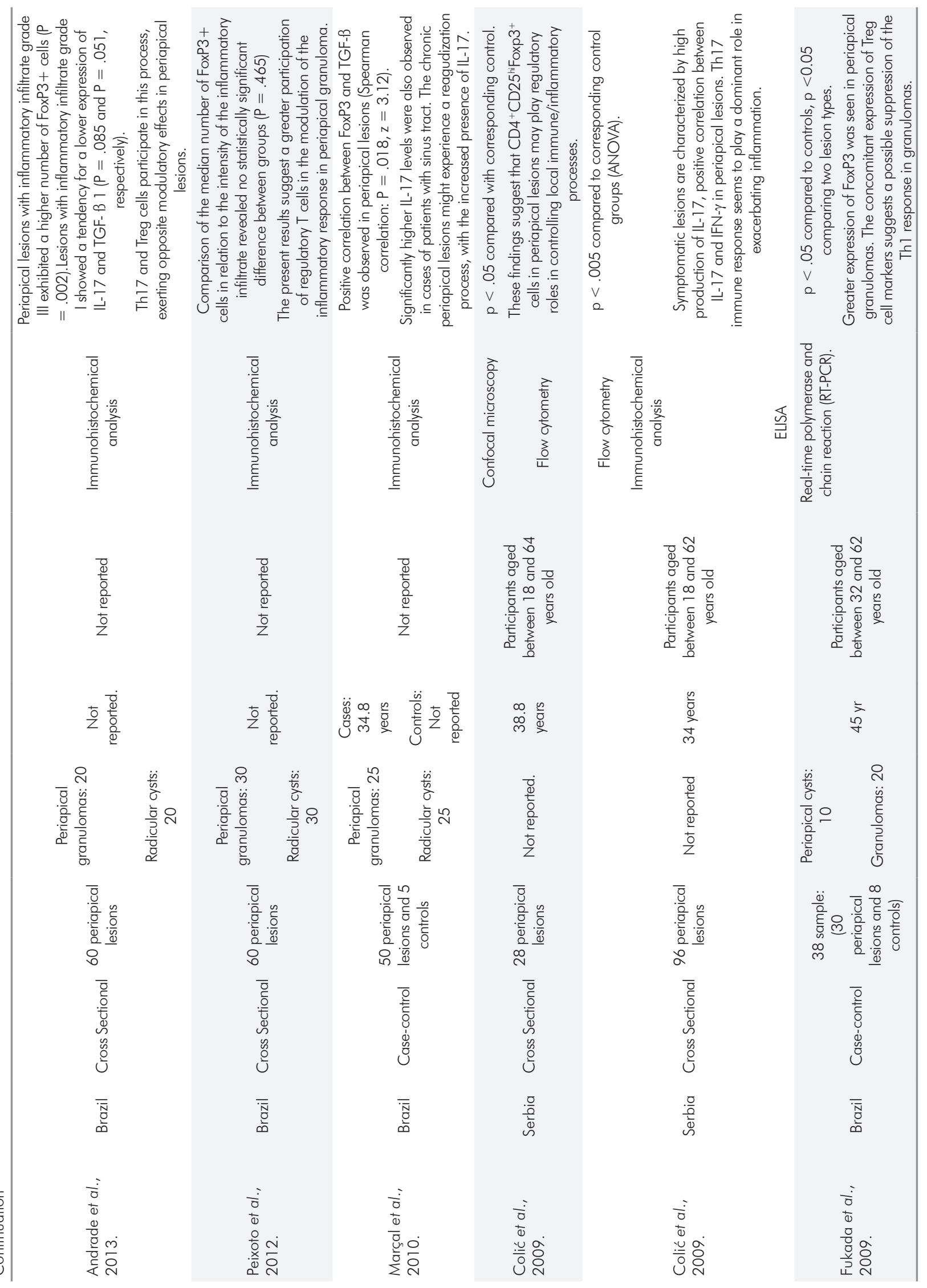


FoxP3 or IL-17, ${ }^{16,17}$ but one study describe the presence of neutrophils linked to a high expression of IL-17.18 Employing different methods, a study also found a higher level of IL-17 in symptomatic lesions; IL-17 was also correlated with neutrophils proportion. ${ }^{20}$

The differences observed between cysts and granulomas in relation to frequency of Treg/Th17 was suggested to contribute to the growth of cysts that are not regulated by the Treg and are influenced by other cytokines. ${ }^{17}$

All studies discussed their results considering the influence of other immunological markers (IL4, IL-9, IL-10, IL-17, IL-21, IL-22, TGF-B, TNF- $\alpha$, IFN$\gamma)$ in the modulation of the Treg/Th17 response and progression of periapical lesions. The effects of this influence are showed in Table 2.

Since Tregs were first characterized in human periapical lesions ${ }^{19}$ knowledge has advanced and molecular studies have contributed to the understanding of the role of Treg/Th17 in periapical disease. The mRNA of multi Th subsets markers, including FoxP3 and IL-17, were evaluated in active and inactive periapical granuloma, determined by the RANKL/OPG analysis. The lesions showed a widespread cytokine expression, however TNF $\alpha$, IL-17, IL-21 and IFN- $\gamma$ were associated with active lesions, while FoxP3, IL-9, IL-4 and IL-22 with lesions inactivity. ${ }^{15}$

A higher expression of IL-10, T-bet and FoxP3 evaluated by RT-PCR was found in periapical granulomas compared with radicular cysts, and was associated with osteoclastic activity. ${ }^{21}$ In a more sophisticated study, the DNA methylation profiles of 22 genes were investigated in a large sample of periapical inflammatory lesions, including periapical granulomas and radicular cysts. FOXP3 gene presented the highest DNA methylation, inversely associated with the mRNA levels. ${ }^{14}$

Taken together, the studies suggest that the balance between Treg and Th17 is critical to the outcome of periapical inflammation determining the expansion or healing of chronic lesions.

\section{Synthesis of results and risk of bias across studies}

Although initially planned, the meta-analysis of the data was not possible due to the high degree of heterogeneity across the included studies. Heterogeneous factors were study design [case control studies ${ }^{14,15,18,21}$ and cross-sectional studies $\left.{ }^{16,17,19,20}\right]$, method of molecular analysis used [ELISA method ${ }^{18,20}$, RT-PCR ${ }^{14,15,21}$, flow citometry ${ }^{19,20}$, confocal microscopy ${ }^{19}$ and immunohistochemistry ${ }^{16,17,18,20}$ ] and type of data analysis done to assess the presence of Th17 and Treg in the progression of periapical lesions [ $p$-value and $r$-value ${ }^{14,19}$, p-value, mean and standard deviation ${ }^{15,20}$, $\mathrm{p}$-value, r-value, mean, standard error of mean and median ${ }^{16}, \mathrm{p}$-value, median and interquartile range $^{17}, \mathrm{p}$-value, median, interquartile range and $z$-value ${ }^{18}, p$-value ${ }^{21}$. Moreover, the studies in which immunohistochemical analysis was used varied in terms of methods adopted [computerized program ${ }^{18}$, three ${ }^{16}$ or one ${ }^{17}$ microscopic fields of each specimen]. Therefore, we carried out a qualitative summary, with the data organized in Table 2 to facilitate a narrative synthesis of this systematic review.

\section{Risk of bias across studies}

The objective of this systematic review was to identify studies and not publications. Nevertheless, multiple publications ${ }^{19,20}$ using the same data pool were selected because they measured the presence of Th17 and Treg in the progression of periapical lesions using different strategies. One article used FoxP3 as the main target of the study ${ }^{19}$, while the second assessed Th17 markers ${ }^{20}$.

\section{Discussion}

\section{Summary of evidence}

This systematic review collected contributions from different studies enabling researchers to understand the key role of Treg and Th17 in inflammatory periapical lesions. Research on the pathogenesis of autoimmune and inflammatory diseases has made significant progress in the past few years, and Th17 and Treg have emerged as major players in autoimmunity. Moreover, the present study allows investigators to be aware of the influence of different immunological markers, such as FoxP3 and IL-17 in this condition. ${ }^{22}$ Treg and Th17 are both present in inflammation sites, but they seem to have opposing roles in the progression of inflammatory periapical lesions. While Th17 stimulate 
the immune response, Treg have a regulatory activity and, therefore, play a very important role in the maintenance of tolerance and in the control of the expansion and activation of the immune system. ${ }^{5}$ The information provided by the studies included in this systematic review might be also relevant for clinical purposes. The Treg/Th17 relationship might help in the understanding of the progressive bone resorption related to periapical lesions. ${ }^{7}$

Studies have demonstrated ${ }^{14,15,16,17,19,21}$ that FoxP3 is a master switch governing the progression and function of Treg, whose functions include the inhibition of the immune response. The inflammatory response featured by FoxP3, IL-10, IL-9, IL-4 and IL-22 contributes to lesions inactivity ${ }^{15}$. On the other hand, Th17 immune response seems to play a dominant role in exacerbating inflammation ${ }^{20}$. In addition, different cytokines such as IL-1, IL- 6 and TNF- $\alpha$ alongside TGF- $\beta$ contribute to the production of IL-1718. Moreover, Treg can produce IL-17 in accordance with the environment ${ }^{15}$. Thus, the participation of Treg and Th17 has been associated with the modulation of human periapical lesions and bone resorption. However, only the simultaneous analysis of a broad cytokine panel can better elucidate the immune regulatory scenario of the periapical inflammatory disease.

Different methods of analysis (RT-PCR, immunohistochemistry, confocal microscopy, flow cytometry, ELISA) were used to evaluate the role of cellular immune response in the progression of periapical lesions. Each of these approaches has advantages and disadvantages. ${ }^{23}$ Confocal microscopy displays cell images in high resolution, but the absolute fluorescence sensitivity is substantially lower than other techniques. Flow cytometry compromises image quality in favor of fluorescence sensitivity and the method has the advantage of performing rapid analysis of a great amount of cells. ${ }^{24}$ RT-PCR is a quantitative method that enables researchers to identify many types of cytokines in small samples. However, the presence of RNA may reflect protein levels and decrease accuracy levels. ${ }^{25}$ ELISA, on the other hand, allows the quantitative detection of cytokines at protein level. While the afore-mentioned protocols cannot identify the cytokine-producing cell types, immunohistochemistry overcomes this deficiency. The identification of these cells may be done in tissues that do not produced sufficient cytokines to be detected by the other approaches. On the other hand, immunohistochemistry does not provide a precise quantitative analysis, as the other methods, and although IL-17 is a marker of Th17 lymphocytes, other cells can express this cytokine. ${ }^{23}$

The role of Treg/Th17 response in inflammatory immune bone resorption has been explored in other diseases. ${ }^{26}$ In rheumatoid arthritis (RA), studies describe an excessive production of IL-17 followed by bone and cartilage destruction. Moreover, Treg in RA are not entirely efficient to control inflammation. A similar mechanism is found in periodontal disease. ${ }^{5,27}$ With respect to the periapical lesion progression, clinical and experimental studies suggest that the balance between Treg and Th17 is critical to the outcomes of periapical lesions in terms of activity (lesion expansion), or inactivity (healing) ${ }^{15,18}$ Higher IL-17 levels were also observed in cases of patients with sinus tract. ${ }^{20}$ Chronic periapical lesions might experience an exacerbation process, with increased presence of IL-17. These data are shown in Table 2.

\section{Limitations}

The lack of quantitative data for meta-analysis could be considered a drawback of the present systematic review. Meta-analysis is not feasible when the data present high levels of heterogeneity. The heterogeneity among the included studies emerged mainly due to the differences in study design, methods of molecular analysis and data summary methods used to report the presence of Th17 and Treg in the progression of periapical lesions precluding any possibility of a pooled estimation of the results. A meta-analysis would have allowed the authors to determine the strength of evidence more precisely. ${ }^{28,29,30}$ Moreover, the qualitative evaluation of in vitro studies does not have a recommended tool in the literature. ${ }^{31}$ Thus, the Newcastle Ottawa scale was adapted to assess the risk of bias within the included articles. Finally, even though the included case-control studies ${ }^{14,15,18,21}$ were classified as high quality assessments, this study design along with the cross sectional design of the other four articles ${ }^{16,17,19,20}$ demand careful interpretation of their results. ${ }^{32}$ 
Caution should also be taken in the interpretation of the findings presented herein, as although the study focused on reliable and specific biomarkers to detect Treg and Th17 other biomarkers are known to be involved in the Treg/Th17 imbalance. ${ }^{14,15}$

\section{Suggestions for future research}

In conclusion, this systematic review confirmed the presence of Treg and Th17 in the progression of periapical lesions. The relationship between the inhibitory characteristic of FoxP3 and the proinflammatory feature of IL-17 in the periapical lesions was also highlighted. However, some of the existing articles ${ }^{33,34}$ addressing this issue were excluded from this systematic review because they used animal experiments in their methodology, which limits the extension of the results to humans.

\section{References}

1. Wei S, Kawashima N, Suzuki N, Xu J, Takahashi S, Zhou M, Koizumi Y, Suda H. Kinetics of Th17-related cytokine expression in experimentally induced rat periapical lesions. Aust Endod J. 2013;39(3):164-70. https://doi.org/10.1111/j.1747-4477.2012.00371.x

2. Francisconi CF, Vieira AE, Biguetti CC, Glowacki AJ, Trombone AP, Letra A et al. Characterization of the protective role of regulatory $T$ cells in experimental periapical lesion development and their chemoattraction manipulation as a therapeutic tool. J Endod. 2016;42(1):120-6. https://doi.org/10.1016/i.joen.2015.09.022

3. Ajuz NC, Antunes H, Mendonça TA, Pires FR, Siqueira JF Jr, Armada L. Immunoexpression of interleukin 17 in apical periodontitis lesions. J Endod. 2014;40(9):1400-3. https://doi.org/10.1016/i.joen.2014.03.024

4. Coffman RL. Related origins of the $T(H) 1-T(H) 2$ model: a personal perspective. Nat Immunol. 2006;7(6):539-41. https://doi.org/10.1038/ni0606-539

5. Noack M, Miossec P. Th17 and regulatory T cell balance in autoimmune and inflammatory diseases. Autoimmun Rev. 2014;13(6):668-77. https://doi.org/10.1016/i.autrev.2013.12.004

6. Chen X, Oppenheim JJ; Chen X1. Th17 cells and Tregs: unlikely allies. J Leukoc Biol. 2014; 95(5):723-31. https://doi.org/10.1189/jlb.1213633

7. Chabbi-Achengli Y, Coman T, Collet C, Callebert J, Corcelli $\mathrm{M}$, $\mathrm{Lin} \mathrm{H}$ et al. Serotonin Is involved in autoimmune arthritis through Th17 Immunity and bone resorption. Am J Pathol. 2016;186(4):927-37. https://doi.org/10.1016/i.ajpath.2015.11.018
Few scientific reports with humans are available in research databases. Therefore, we suggest that further studies evaluating the influence of Treg/Th17 in the progression of human periapical lesions and bone resorption are conducted to generate comparable data allowing a quantitative analysis of the findings. ${ }^{35}$ Additionally, strong future research should also be carried out to overcome the limitations of the included studies and to translate research findings into clinical practice. ${ }^{30}$

\section{Acknowledgments}

This study was supported by the National Council for Scientific Progression (CNPq), the Coordination for the Improvement of Higher Level Education Personnel (CAPES), and the State of Minas Gerais Research Foundation (FAPEMIG), Brazil.
8. Huynh A, DuPage M, Priyadharshini B, Sage PT, Quiros J, Borges CMet al. Control of PI(3) kinase in Treg cells maintains homeostasis and lineage stability. Nat Immunol. 2015;16(2):188-96. https://doi.org/10.1038/ni.3077

9. Yang S, Zhu L, Xiao L, Shen Y, Wang L, Peng B et al. Imbalance of interleukin-17+ T-cell and Foxp3+ regulatory T-cell dynamics in rat periapical lesions. J Endod. 2014;40(1):56-62. https://doi.org/10.1016/i.joen.2013.09.033

10. Queiroz-Junior CM, Silva MJ, Corrêa JD, Madeira MF, Garlet TP, Garlet GP et al. A controversial role for IL-12 in immune response and bone resorption at apical periodontal sites. Clin Dev Immunol. 2010;2010:327417. https://doi.org/10.1155/2010/327417

11. AlShwaimi E, Purcell P, Kawai T, Sasaki H, Oukka M, Campos-Neto A et al. Regulatory T cells in mouse periapical lesions. J Endod. 2009;35(9):1229-33. https://doi. org/10.1016/i.joen.2009.06.006

12. Moher D, Liberati A, Tetzlaff J, Altman DG; PRISMA Group. Preferred reporting items for systematic reviews and meta-analyses: the PRISMA statement. J Clin Epidemiol 2009;62(10):1006-12. https://doi.org/10.1016/i.jclinepi.2009.06.005

13. Wells GA, Shea B, O'Connell D, Peterson J, Welch V, Losos M, Tugwell P. The Newcastle-Ottawa scale (NOS) for assessing the quality of nonrandomized studies in meta analysis. [Date unknown] [acess 2016 May]. Avaiable from: https://www.ohri.ca 
14. Campos K, Franscisconi CF, Okehie V, Souza LC, Trombone AP, Letra A et al. FOXP3 DNA methylation levels as a potential biomarker in the development of periapical lesions. J Endod. 2015;41(2):212-8. https://doi.org/10.1016/i.joen.2014.10.003

15. Araujo-Pires AC, Francisconi CF, Biguetti CC, Cavalla F, Aranha AM, Letra $A$ et al. Simultaneous analysis of $T$ helper subsets (Th1, Th2, Th9, Th17, Th22, Tfh, Tr1 and Tregs) markers expression in periapical lesions reveals multiple cytokine clusters accountable for lesions activity and inactivity status. J Appl Oral Sci. 2014;22(4):336-46. https://doi.org/10.1590/1678-775720140140

16. Andrade AL, Nonaka CF, Gordón-Núñez MA, Freitas RA, Galvão HC. Immunoexpression of interleukin 17 , transforming growth factor $\beta 1$, and forkhead box P3 in periapical granulomas, radicular cysts, and residual radicular cysts. J Endod. 2013;39(8):990-4. https://doi.org/10.1016/i.joen.2013.04.028

17. Peixoto RF, Pereira JS, Nonaka CF, Silveira EJ, Miguel MC. Immunohistochemical analysis of FoxP3+ cells in periapical granulomas and radicular cysts. Arch Oral Biol. 2012;57(9):1159-64 https://doi.org/10.1016/i.archoralbio.2012.02.005

18. Marçal JR, Samuel RO, Fernandes D, Araujo MS, Napimoga MH, Pereira AS et al. T-helper cell type 17/regulatory T-cell immunoregulatory balance in human radicular cysts and periapical granulomas.J Endod. 2010;36(6):995-9. https://doi.org/10.1016/i.joen.2010.03.020

19. Colić M, Gazivoda D, Vucević D, Majstorović I, Vasilijić S, Rudolf R et al. Regulatory T-cells in periapical lesions. J Dent Res. 2009;88(11):997-1002. https://doi.org/10.1177/0022034509347090

20. Colić M, Gazivoda D, Vucević D, Vasilijić S, Rudolf R, Lukić A. Proinflammatory and immunoregulatory mechanisms in periapical lesions. Mol Immunol. 2009;47(1):101-13. https://doi.org/10.1016/i.molimm.2009.01.011

21. Fukada SY, Silva TA, Garlet GP, Rosa AL, Silva JS, Cunha FQ. Factors involved in the Thelper type 1 and type 2 cell commitment and osteoclast regulation in inflammatory apical diseases. Oral Microbiol Immunol. 2009;24(1):25-31. https://doi.org/10.1111/j.1399-302X.2008.00469.x

22. Kuc I, Peters E, Pan J. Comparison of clinical and histologic diagnoses in periapical lesions. Oral Surg Oral Med Oral Pathol Oral Radiol Endod. 2000;89(3):333-7. https://doi.org/10.1016/S1079-2104(00)70098-9
23. Amsen D, de Visser KE, Town T. Approaches to determine expression of inflammatory cytokines. Methods Mol Biol. 2009;511:107-42. https://doi.org/10.1007/978-1-59745-447-6_5

24. Basiii DA, Ortyn WE, Liang L, Venkatachalam V, Morrissey P. Cellular image analysis and imaging by flow cytometry. Clin Lab Med. 2007;27(3):653-70. https://doi.org/10.1016/i.cll.2007.05.008

25. Nolan T, Hands RE, Bustin SA. Quantification of $m R N A$ using real-time RT-PCR. Nat Protoc. 2006;1(3):1559-82. https://doi.org/10.1038/nprot.2006.236

26. Wang M, Tian T, Yu S, He N, Ma D. Th17 and Treg cells in bone related diseases. Clin Dev Immunol. 2013;2013:203705. https://doi.org/10.1155/2013/203705

27. Karthikeyan B, Talwar, Arun KV, Kalaivani S. Evaluation of transcription factor that regulates $T$ helper 17 and regulatory $T$ cells function in periodontal health and disease. J Pharm Bioallied Sci. 2015;7(2):672-6. https://doi.org/10.4103/0975-7406.163602.

28. Friedenreich CM. Methods for pooled analyses of epidemiologic studies. Epidemiology. 1993;4(4):295-302. https://doi.org/10.1097/00001648-199307000-00004

29. Bravata DM, Olkin I. Simple pooling versus combining in meta-analysis. Eval Health Prof. 2001;24(2):218-30. https://doi.org/10.1177/01632780122034885

30. Alemayehu, D. Perspectives on pooled data: the case for an integrated approach. J Data Sci. 2011;9:389-97.

31. Borges GÁ, Rêgo DF, Assad DX, Coletta RD, De Luca Canto G, Guerra EN. In vivo and in vitro effects of curcumin on head and neck carcinoma: a systematic review. J Oral Pathol Med. 2017;46(1):3-20. https://doi.org/10.1111/jop.12455

32. Lucchese A, Gentile E, Romano A, Maio C, Laino L, Serpico R. The potential role of in vivo reflectance confocal microscopy for evaluating oral cavity lesions: a systematic review. J Oral Pathol Med. $2016 ; 45(10): 723$-9. https://doi.org/10.1111/jop.12454

33. He M, Song G, Yu Y, Jin Q, Bian Z. LPS-miR-34a-CCL22 axis contributes to regulatory $T$ cell recruitment in periapical lesions. Biochem Biophys Res Commun. 2015;460(3):733-40. https://doi.org/10.1016/i.bbrc.2015.03.098

34. Velickovic M, Pejnovic N, Mitrovic S, Radosavljevic G, Jovanovic I, Kanjevac T et al. ST2 deletion increases inflammatory bone destruction in experimentally induced periapical lesions in mice. .J Endod. 2015;41(3):369-75. https://doi.org/10.1016/i.joen.2014.11.017

35. Berman NG, Parker RA. Meta-analysis: neither quick nor easy. BMC Med Res Methodol. 2002;2:10. https://doi.org/10.1186/1471-2288-2-10 


\section{Appendix 1: List of studies excluded following full text reading and reasons for the exclusion}

1 - He M, Song G, Yu Y, Jin Q, Bian Z.LPS-miR-34a-CCL22 axis contributes to regulatory T cell recruitment in periapical lesions . Biochem Biophys Res Commun. 2015; 460(3):733-40.

Reason for exclusion: Study using animal samples.

2 - Velickovic M, Pejnovic N, Mitrovic S, Radosavljevic G, Jovanovic I, Kanjevac T, Jovicic N, Lukic A. ST2 deletion increases inflammatory bone destruction in experimentally indeced periapical lesions in mice. .J Endod. 2015 Mar; 41(3):369-75.

Reason for exclusion: Study using animal samples.

3 - Xiao L, Zhu L, Yang S, Lei D, Xiao Y, Peng B. Different correlation of sphingosine-1- phosphate receptor 1 with receptor activator of nuclear factor kappa Bligand and regulatory T cells in rat periapical lesions. J Endod. 2015; 41(4):479-86.

Reason for exclusion: Study using animal samples.

4 - Wei S, Kawashima N, Suzuki N, Xu J, Takahashi S, Zhou M, Koizumi Y, Suda H.Kinetics of Th17 related cytokine expression in experimentally induced rat periapical lesions. Aust Endod J. 2013; 39(3):164-70.

Reason for exclusion: Study using animal samples.

5 - AlShwaimi E, Berggreen E, Furusho H, Rossall JC, Dobeck J, Yoganathan S, Stashenko P, Sasaki H. IL-17 receptor A signaling is protective in infection-stimulated periapical bone destruction. J Immunol. 2013; 191(4):1785-91.

Reason for exclusion: Study using animal samples.

6 - AlShwaimi E, Purcell P, Kawai T, Sasaki H, Oukka M, Campos-Neto A, Stashenko P.Regulatory T cells in mouse periapical lesions. J Endod. 2009; 35(9):1229-33.

Reason for exclusion: Study using animal samples.

7 - Xiong H, Wei L, Peng B. Immunohistochemical localization of IL-17 in induced rat periapical lesions. J Endod. 2009; 35(2):216-20.

Reason for exclusion: Study using animal samples.

8 - Yang S, Zhu L, Xiao L, Shen Y, Wang L, Peng B, Haapasalo M. Imbalance of interleukin-17+ T-cell and Foxp3+ regulatory T cell dynamics in rat periapical lesions.J Endod. 2014; 40(1):56-62.

Reason for exclusion: Study using animal samples.

9 - Ferreira LG, Rosin FC, Corrêa L. Analysis of Interleukin 17A in periapical abscess and granuloma lesions. BOR. 2016; vol30.0034.

Reason for exclusion: Not reviewed FoxP3.

10 - Campos K; Franscisconi CF; Okehie V; de Souza LC; Trombone AP; Letra A; Garlet GP; Gomez RS; Silva RM. 4. FOXP3 DNA methylation levels as a potential biomarker in the development of periapical lesions.

J Endod. 2015; 41(2):212-8.

Reason for exclusion: Not reviewed Th17 cells. 


\section{Appendix 2: Quality assessment of included cross-sectional studies based on the Newcastle-Ottawa scale}

\begin{tabular}{|c|c|c|c|c|c|c|}
\hline \multirow[b]{2}{*}{ Author } & \multicolumn{2}{|r|}{ Selection ${ }^{*}$} & \multirow{2}{*}{$\begin{array}{c}\text { Comparability }^{* *} \\
\text { Control for confounders }{ }^{3}\end{array}$} & \multicolumn{2}{|c|}{ Outcome ${ }^{* * *}$} & \multirow[b]{2}{*}{ Score ${ }^{\ldots+*}$} \\
\hline & $\begin{array}{c}\text { Definition of } \\
\text { test }^{1}\end{array}$ & $\begin{array}{l}\text { Representativeness and } \\
\text { selection of individuals } \\
\text { with periapical lesions }\end{array}$ & & $\begin{array}{c}\text { Diagnosis of } \\
\text { periapical lesions }\end{array}$ & $\begin{array}{l}\text { Response } \\
\text { rate }^{5}\end{array}$ & \\
\hline Andrade et al., 2013. & $\star$ & $\star$ & & & & 2 \\
\hline Peixoto et al., 2012. & $*$ & $*$ & & $\star$ & & 3 \\
\hline Colić et al., 2009. & $\star$ & $\star$ & & & & 2 \\
\hline Colić et al., 2009. & $\star$ & $\star$ & & & & 2 \\
\hline
\end{tabular}

"a maximum of 1 point for each item; "a maximum of 2 points for each item; "*a maximum of 1 point for each item

*..." a maximum of 6 points

* 1 point

'a) secure record (eg Real-time polymerase chain reaction, Immunohistochemical analysis, Confocal microscopy, Flow cytometry, ELISA) *,

b) written self report or medical record only, c) no description

${ }^{2}$ a) individuals with periapical lesion in a defined catchment area or community, random sample, sample calculation $*$, b) not satisfying requirements in part (a) fully, c) not stated

${ }^{3}$ a) study control for periapical lesion $*$, b) study control for 2 or more confounding variables $* *$

${ }^{4}$ a) periapical lesions diagnosis was performed based on histopathological and radiographic analysis $\star$, b) based on self reports or not satisfying requirements in part (a) fully, c) no description

${ }^{5}$ a) rate of sample loss $\leq 20 \% *$, b) rate of sample loss $>20 \%$, c) not stated 


\section{Appendix 3: Quality assessment of included case control studies based on the Newcastle-Ottawa scale}

\begin{tabular}{|c|c|c|c|c|c|c|c|c|c|}
\hline \multirow[b]{2}{*}{ Author } & \multicolumn{4}{|c|}{ Selection* } & \multirow{2}{*}{$\begin{array}{l}\text { Comparability** } \\
\text { Comparability of } \\
\text { case controls on } \\
\text { the basis of the } \\
\text { design or analysis }{ }^{5}\end{array}$} & \multicolumn{3}{|c|}{ Outcome e $^{* * *}$} & \multirow[b]{2}{*}{ Score ${ }^{* * * *}$} \\
\hline & $\begin{array}{l}\text { Is the case } \\
\text { definition } \\
\text { adequate? }\end{array}$ & $\begin{array}{c}\text { Representativeness } \\
\text { of the cases }\end{array}$ & $\begin{array}{c}\text { Selection } \\
\text { of } \\
\text { Controls }^{3}\end{array}$ & $\begin{array}{c}\text { Definition } \\
\text { of } \\
\text { Controls }\end{array}$ & & $\begin{array}{c}\text { Assessment } \\
\text { of } \\
\text { exposure }^{6}\end{array}$ & $\begin{array}{c}\text { Same } \\
\text { method of } \\
\text { ascertainment } \\
\text { for cases and } \\
\text { controls }^{7}\end{array}$ & $\begin{array}{c}\text { Non-Response } \\
\text { rate }^{8}\end{array}$ & \\
\hline $\begin{array}{l}\text { Campos } \\
\text { et al., } 2015 .\end{array}$ & 妨 & $\star$ & $\star$ & $\star$ & $\star$ & $\star$ & $\star$ & $\star$ & 8 \\
\hline $\begin{array}{l}\text { Araujo-Pires } \\
\text { et al., } 2014 .\end{array}$ & $\star$ & $\star$ & $\star$ & $\star$ & $\star$ & $\star$ & $\star$ & * & 8 \\
\hline $\begin{array}{l}\text { Marçal et al. } \\
2010 .\end{array}$ & $\star$ & $\star$ & & $\star$ & $\star$ & $\star$ & $\star$ & $\star$ & 7 \\
\hline $\begin{array}{l}\text { Fukada } \\
\text { et al. } 2009 .\end{array}$ & $\star$ & $\star$ & $\star$ & $\star$ & $\star$ & * & $\star$ & $\star$ & 8 \\
\hline
\end{tabular}

"a maximum of 1 point for each item; "a maximum of 2 points for each item; "**a maximum of 1 point for each item

**** maximum of 9 points

* 1 point

' a) yes, with independent validation $*$, b) yes, eg record linkage or based on self reports, c) no description

2 a) consecutive or obviously representative series of cases $*$, b) potential for selection biases or not stated

${ }^{3}$ a) community controls $*$, b) hospital controls, c) no complete description

${ }^{4}$ a) no history of disease (endpoint) $*$, b) no description of source

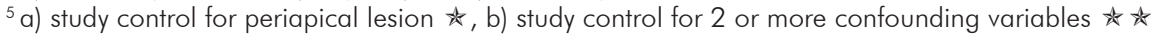

${ }^{6}$ a) secure record (eg Real-time polymerase chain reaction, Immunohistochemical analysis, Confocal microscopy ,Flow cytometry, ELISA) Ł, b)

written self report or medical record only, c) no description

7 a) yes $*$, b) no

${ }^{8}$ a) same rate for both groups $*$, b) non respondents described, c) rate different and no designation 